\title{
Will the learners be learned?
}

In a time of drastic change it is the learners who inherit the future. The learned usually find themselves equipped to live in a world that no longer exists.

-Eric Hoffer

One can argue just how drastic the changes in medicine will be as the genetics revolution is realized. What is less controversial is that changes are coming and that they will impact all providers. Awareness of this impact has been in the consciousness of both the genetics and primary care communities, but the driving forces of change have shifted recently. Now the genetics community is needing to push less as the community of primary care providers starts to pull.

From the literature of the past decade on the role of primary care providers (PCPs) in the delivery of genetics services, two points come through clearly. First, PCPs recognize their need for greater education and training. This has been well-documented among a diverse range of providers in a variety of delivery systems from around the world. ${ }^{1-14}$ Based on these studies, we may fairly generalize that the needs are universal and pressing. PCPs have indicated that they are uncomfortable with many genetics concepts, that they are not sufficiently trained to provide even basic genetic counseling, and that they lack knowledge of genetics resources.

In this issue of Genetics in Medicine, the article by Metcalfe et al. ${ }^{14}$ effectively underscores a second, more subtle point that echoes the literature: PCPs want to have a substantial hand in determining what they are taught about genetics and how. Early in the past decade, most physicians were unconvinced of the relevance of genetics to their practice. ${ }^{5} \mathrm{~A}$ significant shift has occurred since then. Now, the relevance is taken for granted and the prevailing sentiment is that PCPs should play a central role in defining the content and scope of genetics training. What is less clear is the role the genetics community will play in this educational process.

Every expert on educational methods acknowledges the importance of trainees' needs in driving curriculum development. This fact informed the decision by the Genetics Services Branch of the Maternal and Child Health Bureau, Health Resources and Services Administration, to create training programs in genetics for physicians in primary care (http://bhpr.hrsa.gov/dm/genpc.html). These programs, by PCPs for PCPs, wisely have focused on faculty development. If successful, these new programs will ultimately reach many physicians and do so at an early stage in their careers. That's all good news. What is uncertain is whether these programs will address the fundamental cognitive shift required for providers to consider genetics in every patient encounter. This shift is not what PCPs are asking for but more what the genetics community is hoping for.

PCPs are asking for instruction on specific content, and there is no debate about this need. However, with the rapid pace of change in genetic medicine, specific content will fall short of what PCPs really need. If primary care genetics education focuses only on imparting information, a great opportunity to impact real change will be lost. PCPs are requesting algorithms to help them manage patients with genetic disorders and decide when to refer them to a specialist. The most cited examples are guidelines related to patients with family histories of cancer, ${ }^{15-17}$ but this will expand over the next few decades to include many common multifactorial disorders. Much of the motivation to distill medical decision-making to algorithms comes from pressure to standardize care and measure outcomes. With no additional training and their current cognitive strategy, most physicians can readily apply an algorithm to the care of a wheezing patient. But for patients with inherited cancer risk, the algorithm is complex and demands both a broad knowledge of genetics and a different cognitive strategy. The algorithm alone is not enough. In fact, a genetics-naive physician attempting to apply a family cancer algorithm may cause harm to his or her patients.

A thoughtful, deliberate, and informed refinement of the "usual" cognitive strategies will have the greatest impact on integrating genetics thinking into all of health care. The clinical reasoning skills being applied by most physicians fall short when rarity, variable expressivity, incomplete penetrance, and pleiotropy come into play. These are also the reasons why imparting information about genetic disorders would serve relatively few patients; most don't fit the textbook case. The real challenge in creating a workforce to deliver primary-level genetics services ${ }^{18}$ is finding ways to help PCPs raise genetic hypotheses or "think genetically" with every patient. Patients seen in the primary care setting do not fit neatly into categories based on illness, gender, or age. The PCP already applies a critical perspective based on the individual in the context of his or her family and community. Medical geneticists use these same skills and are well-positioned to assist PCPs in developing genetics thinking as it applies to all patients.

Strategies have been suggested to help primary care physicians overcome common barriers to recognizing and diagnosing genetic disease. They help physicians develop clinical reasoning skills and heuristics that address these barriers and increase the likelihood that a genetic hypothesis will be considered. They may ultimately enable PCPs to apply a range of genetics algorithms wisely. The strategies were proposed by Worthen, ${ }^{19}$ a primary care physician who is especially insightful about his own evolution toward genetics thinking and, frankly, rather genetics-sophisticated. They are as follows: (1) set a low threshold for genetic hypotheses; (2) try to develop a unifying hypothesis for disparate findings; (3) maintain and update the pedigree; (4) look for clues in presentation and setting; (5) distinguish sporadic, familial, and inherited cases; (6) consider variation; (7) become familiar with resources; and (8) allow time. The last strategy may be the most substantial barrier to PCPs delivering primary-level genetics services. It takes time to address issues of confidentiality and genetic 
discrimination, to inform patients about complex concepts, and to obtain consent for genetic testing. Time is in short supply for most PCPs, who are driven increasingly by the demand to see more patients in a shorter period of time. The current structure of insurance reimbursement does not adequately compensate providers for the time needed for many genetics services. As more nongeneticist providers begin to deliver genetics services, the value and compensation attached to these services may increase. Furthermore, better outcome measures may be developed that reflect the value that patients place on genetics services.

In primary care genetics training, a focus on process at least as much as content will best prepare providers to think critically about many of the important concerns raised by this genetics revolution. Introduction of these strategies early in medical education by providers in a wide range of specialties will facilitate their adoption and integration into medical thinking. The current generation of medical students is growing up during the genetics revolution in medicine, but how much are they really learning about how it will impact their practice? Are they learning to "think genetically"?

The primary care specialties have a substantial role in building a workforce to deliver primary-level genetics services. But a fundamental change is required in how genetics is integrated into daily medical thinking and decision-making and into medical education. For that, the genetics community can help to bring about change and, indeed, progress.

Change is one thing, progress is another. "Change" is scientific, "progress" is ethical; change is indubitable, whereas progress is a matter of controversy.

—Bertrand Russell

Susan J. Hayflick, $M D^{1}$ M. Patrice Eiff, $M D^{2}$

${ }^{1}$ Molecular and Medical Genetics, Pediatrics and Neurology ${ }^{2}$ Family Medicine

Oregon Health \& Science University

Portland, Oregon

\section{References}

1. Hofman KJ, Tambor ES, Chase GA, Geller G, Faden RR, Holtzman NA. Physicians' knowledge of genetics and genetic tests. Acad Med 1993;68:625-632.

2. Viljoen D, Beighton P, Hitzeroth $\mathrm{H}$. Medical genetics in primary health care. $S$ Afr Med J 1995;85:1-3.

3. Friedman LC, Plon SE, Cooper HP, Weinberg AD. Cancer genetics: survey of primary care physicians' attitudes and practices. J Cancer Educ 1997;12:199-203.

4. Harris R, Harris H. Genetics in primary care. Report on workshop of EC Concerted Action on Genetics Services in Europe (CAGSE) in association with the Royal College of GP Spring Meeting, Blackpool, UK, 28 April 1995. J Med Genet 1996;33:346348.

5. Hayflick SJ, Eiff MP, Carpenter L, Steinberger J. Primary care physicians' utilization and perceptions of genetics services. Genet Med 1998;1:13-21.

6. Carroll JC, Heisey RE, Warner E, Goel V, McCready DR. Hereditary breast cancer: psychosocial issues and family physicians' role. Can Fam Physician 1999;45:126132.

7. Emery J, Watson E, Rose P, Andermann A. A systematic review of the literature exploring the role of primary care in genetic services. Fam Pract 1999;16:426-445.

8. Kolb SE, Aguilar MC, Dinenberg M, Kaye CI. Genetics education for primary care providers in community health settings. J Community Health 1999;24:45-59.

9. Watson EK, Shickle D, Qureshi N, Emery J, Austoker J. The "new genetics" and primary care: GPs' views on their role and their educational needs. Fam Pract 1999; 16:420-425.

10. Escher M, Sappino AP. Primary care physicians' knowledge and attitudes towards genetic testing for breast-ovarian cancer predisposition. Ann Oncol 2000;11:11311135 .

11. Sandhaus LM, Singer ME, Dawson NV, Wiesner GL. Reporting BRCA test results to primary care physicians. Genet Med 2001;3:327-334.

12. Emery J, Hayflick $S$. The challenge of integrating genetic medicine into primary care. BMJ 2001;322:1027-1030.

13. Peterson SK, Rieger PT, Marani SK, deMoor C, Gritz ER. Oncology nurses' knowledge, practice, and educational needs regarding cancer genetics. Am J Med Genet 2001;98:3-12.

14. Metcalfe S, Hurworth R, Newstead J, Robins R. Needs assessment study of genetics education for general practitioners in Australia. Genet Med 2002;4:71-77.

15. Fry A, Campbell H, Gudmunsdottir H, Rush R, Porteous M, Gorman D, Cull A. GPs' views on their role in cancer genetics services and current practice. Fam Pract 1999;16:468-474.

16. de Bock GH, Vlieland TP, Hakkeling M, Kievit J, Springer MP. GPs' management of women seeking help for familial breast cancer. Fam Pract 1999;16:463-467.

17. de Bock GH, Vlieland TP, Hageman GC, Oosterwijk JC, Springer MP, Kievit J. The assessment of genetic risk of breast cancer: a set of GP guidelines. Fam Pract 1999; $16: 71-77$.

18. Hayflick SJ, Eiff MP. The role of primary care providers in the delivery of genetics services. Community Genet 1998;1:18-22.

19. Worthen HG. Inherited cancer and the primary care physician: barriers and strategies. Cancer 1999;86:2583-2588. 